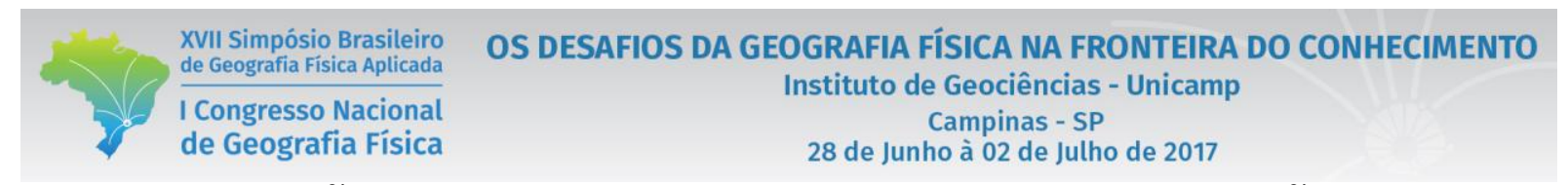

\title{
PRODUÇÃO DO ESPAÇO URBANO E A APROPRIAÇÃO DOS RECURSOS HÍDRICOS EM PALMAS, TO
}

\author{
Clóvis Cruvinel da Silva Júnior ${ }^{(a)}$, Antonio Carlos Vitte ${ }^{(b)}$ \\ (a) Instituto de Geociencias UNICAMP/ Programa de Pós-Graduação em Geografia - cloviscruvinel@uft.edu.br \\ (b) Instituto de Geociencias UNICAMP/ Programa de Pós-Graduação em Geografia - acarlosvitte@ gmail.com
}

\section{EIXO: BACIAS HIDROGRÁFICAS E RECURSOS HÍDRICOS: ANÁLISE, PLANEJAMENTO E GESTÃO}

\begin{abstract}
Resumo
O manejo dos recursos hídricos em aglomerações urbanas, depois da criação da Política Nacional de Recursos Hídricos e da promulgação do Estatuto da Cidade, que estabelece e direciona os planos diretores como principal instrumento de gestão das cidades, vem enfrentando entraves complexos, devido principalmente à ausência de ordenamentos territoriais relacionados diretamente com as políticas hídricas. Diante desses apontamentos, este artigo norteia-se a partir da problemática da produção do espaço e suas consequências para a gestão hídrica frente ao descompasso com as políticas urbanas em Palmas, TO. Tem o objetivo de apontar, bem como o de refletir sobre a lógica produtiva do espaço urbano de Palmas, frente aos descompassos das políticas públicas, na apropriação e gestão dos recursos hídricos, evidenciando as implicações de uma lógica dicotômica e descompassada de gestão entre dois "alicerces" na discussão e elaboração do desenvolvimento urbano de qualquer cidade: a produção do espaço urbano e os recursos hídricos.
\end{abstract}

Palavras chave: Palmas; Recursos hídricos, Produção do Espaço, gestão urbana.

\section{Introdução}

A cidade é um produto da ação contínua de sua sociedade, do estado e do capital privado e como consequência sempre refletirá os atos sociais, econômicos e políticos de seus agentes. Harvey (2005, p.165) explica que uma cidade é "tanto o produto, como condição dos processos sociais de transformação em andamento, na fase mais recente do desenvolvimento capitalista". No caso de Palmas, uma cidade produzida desde sua gênese por estes agentes, a concepção urbana reflete diretamente em seu território natural, criando e gerando alterações na apropriação destes recursos, especificamente os recursos hídricos.

Diante desta afirmação, é relevante entender que a atual degradação dos recursos hídricos é um dos fatores que limita as condições de vida de parte significativa da população do planeta, colocando em xeque as possibilidades da continuidade do desenvolvimento em suas diversas dimensões (JACOBI apud RIBEIRO, 2008, p.13). O rápido e desordenado crescimento das cidades, quase sempre devido a forma como este espaço é produzido (grifo nosso), vem 
forçando, cada vez mais, a apropriação e exploração (grifo nosso) dos recursos hídricos, já em seu limite máximo de consumo (CLARKE e KING, 2005, p.67).

A sociedade concentrada em cidades enfrenta maiores desafios para obter água de qualidade, conforme nos ensina Ribeiro (2008). Acrescentamos à afirmativa do autor, o desafio da quantidade na mesma proporção ${ }^{1}$. Corroborando com o autor, entendemos que o crescimento populacional não ocorre de maneira uniforme no planeta e os problemas de acesso à infraestrutura urbana, à qualidade e quantidade de água fica mais acentuada, ao passo que, as cidades deixem surgir espaços segregados sem a presença mínima de equipamentos urbanos e serviços de abastecimento de água, coleta e tratamento de esgoto para toda população da cidade.

É preciso entender de forma reflexiva como este espaço é produzido e quais são as dinâmicas para se produzir espaços com menores impactos aos recursos naturais, aqui especificamente analisado, os recursos hídricos, para não ocorrer sua escassez e acentuar o processo de degradação do mesmo - processo de produção destrutiva (Rodrigues, 1998, p.27). Ratifica-se que a concentração da população brasileira nas áreas urbanas, aliada às restrições econômicas que atingem a sociedade e às "limitações" das administrações públicas em relação ao planejamento, ao controle do uso e ocupação do solo e à gestão hídrica dos mananciais urbanos, reforça o caráter informal e aparentemente anárquico da urbanização brasileira. Tais características se expressam no agravamento dos processos de segregação espacial, de exclusão social, de degradação ambiental, ou seja, na forma como o espaço de cada "lugar" é produzido.

A exemplo de Palmas, TO é importante compreender que as manchas urbanas, não diferentemente de outros centros, exigem cada vez mais água para suprir as necessidades de seus habitantes, sendo um problema de ordem complexa prover água a população das cidades (Ribeiro, 2008). Desta forma, é imprescindível que o desenvolvimento urbano tenha como objetivo melhorar a qualidade de vida da população e a conservação ambiental, além de se tornar integrador à medida que a relação natureza x homem se estabeleça de maneira equilibrada (TUCCI 2005). Este desenvolvimento deve preceder de políticas que vislumbrem as águas

\footnotetext{
${ }^{1}$ A causa da principal falta de água em cidades são a degradação dos mananciais, vazamentos no sistema de distribuição (que em média chega a 20\%), e degradação da água subterrânea devido ao contato com o material poluidor, como chorume resultante da deposição inadequada dos resíduos sólidos urbanos (RIBEIRO 2008, P.34).
} 


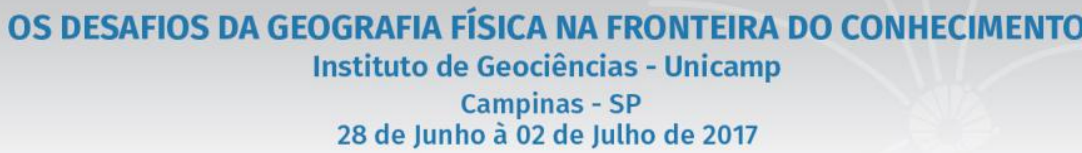

urbanas $^{2}$ e as múltiplas e diferentes formas em que este espaço é produzido e ocupado. É evidente, a necessidade de se articular a gestão dos mananciais hídricos urbanos e seus múltiplos usos a todo processo de planejamento local, conjugando-os com os instrumentos de gerenciamento de modo que os agentes sociais, políticos, econômicos e ambientais estejam interligados na produção e no ordenamento do espaço urbano. Galindo (2008) neste sentido explica que

[...] as legislações urbanísticas municipais precisam estabelecer parâmetros para uma gestão integrada, que comtemple não apenas aspectos de ordenamento territorial, mas que deem conta de questões ambientais que se expressem no território, possibilitando reverter à lógica de uso e ocupação do espaço urbano local, geradora de diversos problemas sócio ambiental.

A gestão integrada de recursos hídricos, da forma como hoje vem sendo compreendida na literatura nacional e internacional (Dourojeanni e Jouravlev, 2001), tem como principais fundamentos o uso equilibrado dos recursos, a abordagem multisetorial e o emprego de medidas não estruturais, entre as quais se destaca a gestão de demanda. Essa concepção ampla da gestão dos recursos é um quase corolário do conceito de desenvolvimento sustentável, que associa o processo de desenvolvimento à equidade social e à manutenção da capacidade de suporte dos sistemas ambientais (Muñoz, 2000).

Palmas, a exemplo de outras cidades brasileiras, vive um momento de transformação no que se refere ao processo de planejamento e gestão urbana hídrica. Galindo (2008, p.2) nos explica que o Estatuto da Cidade, ao determinar que os municípios elaborassem planos diretores, possibilitou não apenas a regulação dos processos espaciais e do desenvolvimento urbano, mas, a busca de soluções para os principais problemas que afligem a maioria dos municípios, principalmente, aqui sublinhado por nós, os de ordem hídrica.

Contudo, salvo as exceções, a produção dos territórios urbanos tem contribuído de modo decisivo à degradação dos recursos hídricos, principalmente pela rápida e desordenada expansão urbana, com inúmeros efeitos diretos e indiretos, alterando substancialmente a drenagem e produzindo problemas à saúde humana, além de impactos como enchentes, deslizamentos e

2 Tucci $(2008$, p. 3) no ensina que as águas urbanas englobam o sistema de abastecimento de água e esgotos sanitários, a drenagem urbana, e as inundações ribeirinhas, tendo como metas a saúde e a conservação ambiental. 
desastres provocados pelo desequilíbrio no escoamento das águas ${ }^{3}$ (TUNDISI E TUNDISI, 2011, p, 68). O impacto na produção da cidade nas águas dos rios que cortam e margeiam as mesmas ocorre, assim, tanto em aspectos de alteração na qualidade quanto na alteração do ciclo hidrológico, com mudança nos padrões de fluxo e quantidade da água (FINOTTI et al, 2009, p.46). Portanto, deve-se levar em consideração, a gestão das águas urbanas, à medida que a população cresce, que a cidade é produzida, pois na maioria das vezes, por falta de um "ordenamento territorial-ambiental”, estes espaços são produzidos com problemas de ordem espacial e hídrica ${ }^{4}$.

O estudo e monitoramento frente à produção espacial urbana estabelece diretamente mecanismos de controle sobre os mananciais, sobre o uso e a ocupação do território de forma ordenada. Ademais, a cidade constituída de parcelamentos fragmentados por meio de "ocupações desordenadas e conflitantes" $" 5$ aliada a interesses específicos da gestão pública e do capital imobiliário gera quase que frequentemente ordenamentos unilaterais com sequelas para os espaços urbanos de modo geral, especificamente em relação a apropriação dos recursos hídricos como é o caso de Palmas.

Corroborando com Beer (1990) a expansão das cidades na maioria das vezes não observa a relação intrínseca que deve haver entre a gestão do solo e a gestão hídrica de qualquer espaço urbano gerando nestes lugares uma "produção e reprodução contínua de externalidades e cenários de insustentabilidade territorial urbana", Esta afirmação vai de encontro aos ensinamentos de Tundisi e Tundisi (2011, p, 125) que diz que,

[...] O crescimento da população urbana no Brasil promoveu um aumento considerável das demandas hídricas, associado à expansão urbana, degradação dos mananciais, contaminação e poluição e outras alterações. Estas alterações no ciclo hidrológico, por exemplo, produzidas pela inadequada ocupação do espaço, geram frequentes enchentes

\footnotetext{
${ }^{3}$ Já presenciados em Palmas (uma cidade dita politicamente projetada e planeja), principalmente nos últimos 5 anos.

4 A título de exemplo podemos citar que o desenvolvimento dos centros urbanos geralmente significa aumento na impermeabilização do solo pela pavimentação das ruas e lotes, construção de moradias e outras obras de infraestrutura (FINOTTI et al, 2009, p.46). No caso de Palmas, a evolução urbana segue todos estes problemas e outros, mesmo tendo um projeto e um planejamento que deveria ser seguido nas gestões municipais ao longo dos anos.

${ }^{5} \mathrm{O}$ processo de urbanização das cidades brasileiras é desenvolvido e caracterizado predominantemente por meio do parcelamento do solo na abertura de franjas de expansão de loteamentos e desmembramento de glebas. Tal processo vem se desenvolvendo de maneira dissociada de um planejamento integrado, e sem a incorporação da dimensão temporal nas ações que guiam a ocupação do espaço, determinada em grande parte por especuladores que buscam maior lucro no menor tempo possível (BOTTARI, 2005).

${ }^{6}$ Os efeitos do processo de desenvolvimento urbano refletem sobre toda a infraestrutura urbana, em particular sobre aquela relativa a recursos hídricos (sistema sanitário, sistema de abastecimento de água, e sistema pluvial) gerando impactos de nat ureza diversos (sociais, econômicos e ambientais) em função do inadequado gerenciamento da água conforme nos ensina Godim Filho e Medeiros (2004).
} 
urbanas, problemas na coleta e disposição do lixo urbano, que resultam em contaminação dos aquíferos e águas superficiais, e perdas na distribuição. [...] a ocupação desordenada e irregular de mananciais nas áreas periurbanas é uma das principais causas de deterioração de recursos hídricos em grandes metrópoles brasileiras, assim como município de médio porte.

Destarte, de acordo com Souza (2000) a gestão hídrica e urbana das cidades deve ocorrer equilibrando a espacialidade, a temporalidade e participação da sociedade. Eis um paradigma das políticas públicas e hídricas urbanas a ser compreendido, analisado e aplicado. A gestão das águas urbanas necessita levar em consideração todas as atividades relacionadas com o uso e ocupação do solo, bem como o uso e controle dos recursos hídricos de uma bacia hidrográfica urbana, pois são e estão vinculadas pelo movimento da água através do seu território. Esta é a ligação basilar entre a necessidade de estabelecer relação entre o ordenamento territorial a partir de planejamentos e da gestão da água no meio urbano (Godim Filho e Medeiros, 2004). Desse modo, o desafio da gestão hídrica e urbanística é articular as políticas públicas de ordenamento territorial, às técnicas relacionadas à escolha do sistema e, consequentemente, da forma de gestão da infraestrutura a ser adotadas. Nas cidades, contudo, não há articulação, ou quando há, não funciona.

Um exemplo clássico é a configuração da infraestrutura viária, assim como de esgoto e drenagem, que está a reboque de um desenvolvimento urbano. Faz-se necessário que os planos diretores, que regulam o ordenamento territorial urbano por meio de suas diretrizes enunciem políticas integradas de desenvolvimento por e para o meio ambiente sem dicotomias e não atendam somente a demanda da ordem de um mercado imobiliário ou de políticas públicas isoladas. A cidade, assim, evoluíra de forma ordenada, integrada e sistematizada com o meio ocupado. Contudo, o que se observa ao longo do tempo das cidades, é o inverso, visto que conforme nos explica Carneiro e Miguez (2011) não obstante os avanços recentes em gestão integrada e participativa, os projetos setoriais de impacto nos recursos hídricos continuam sendo implantados sem negociação prévia com os órgãos responsáveis pelo gerenciamento dos recursos hídricos, muito menos juntos. Aqui acrescentamos, o departamento responsável pelo uso do solo urbano.

Destarte, existe uma relação indissociável entre o ordenamento territorial urbano e a gestão das águas. Neste sentido, Carneiro e Miguez (2011, p.71) explicam que a abordagem atual 
acerca do gerenciamento dos recursos hídricos nas áreas urbanas pressupõe um planejamento indissociável e integrado aos planos de desenvolvimento urbano. Para Tucci (2004) esta abordagem entre a gestão do solo e das águas urbanas (proteção de mananciais, coleta e tratamento de esgotos sanitários, coleta e disposição de resíduos sólidos, drenagem urbana, inundações ribeirinhas e uso solo) deve ser analisada e tratada de forma unicamente integrada, sempre considerando como núcleo central de ação o Plano de desenvolvimento urbano. Todavia, Gouvêa (2005) explica que a dinâmica do crescimento das cidades, em sua maioria, de forma desordenada, como é o de Palmas, demonstra gradativamente a ineficiência dos inúmeros programas e projetos implementados em módulos isolados e desenvolvidos a partir da ideia equivocada de que a realidade urbana poderia ser dividida e tratada de maneira compartimentada e estanque, sem gerar maiores implicações para os recursos hídricos e para os espaços urbanos de modo geral.

Baseado nestas arguições, este artigo busca apontar e refletir de forma objetiva sobre a lógica produtiva do espaço urbano de Palmas desde sua criação, frente aos descompassos das políticas públicas, na apropriação e gestão dos recursos hídricos, evidenciando as implicações de uma lógica dicotômica e descompassada de gestão entre dois "alicerces" na discussão e elaboração do desenvolvimento urbano de qualquer cidade: a produção do espaço urbano e os recursos hídricos. Para tanto, a metodologia de análise buscou intermediar associações entre os dados empíricos, conceitos e as teorias já apresentadas pela literatura sobre a produção do espaço e a relação com a apropriação e gestão dos recursos hídricos, como as dimensões que envolvem estes dois pontos de análise ${ }^{7}$.

\section{A Produção urbana e a relação com os recursos hídricos em Palmas.}

Como já apontado neste texto, o manejo dos recursos hídricos em aglomerações urbanas, depois da criação da Política Nacional de Recursos Hídricos e da promulgação do Estatuto da Cidade, vem enfrentando entraves devido principalmente à ausência ordenamentos territoriais. Tais ordenamentos implicam na concepção de que as políticas de uso dos recursos hídricos são

\footnotetext{
${ }^{7}$ Os dados apresentados neste artigo, são resultados das primeiras análises sobre a produção do espaço urbano em Palmas, TO, objeto de estudo de doutoramento do primeiro autor sob a orientação do segundo.
} 
instrumentos essenciais na ordenação e na subsequente produção do espaço urbano de qualquer cidade. O uso desse recurso requer políticas de planejamento estruturadas a partir das gestões diretas e indiretas dos agentes locais, que muitas vezes não conseguem acompanhar a velocidade em que o espaço é produzido. Assim, essas considerações remetem a ideia e "(re)coloca em destaque e debate, as contradições da produção social do espaço e as formas de como a natureza é apropriada” (RODRIGUES,1998, p.13).

$\mathrm{Na}$ verdade, as relações entre a produção do espaço urbano em Palmas e suas consequências para os recursos hídricos trazem inquietações sobre como o espaço urbano se configura ante a necessidade de se ordenar e equilibrar o uso deste recurso para atender a demanda de toda a cidade e, assim, evitar conflitos de escassez, poluição, má drenagem e segregação pela distribuição espacial da população existentes desde sua criação. É uma relação intrínseca, pois, de acordo com Almeida e Pereira (2009, p.89-91), a água,

[...] enquanto elemento essencial à vida no planeta inevitavelmente direciona a tendência de ocupação do território. Isto é, claro, sempre que possível, já que a lógica não impediu que houvesse ocupações em áreas com pouca disponibilidade hídrica [...] as taxas de crescimento de inúmeras áreas ribeirinhas demonstram que a pressão sobre esses ecossistemas é cada vez maior, resultante da expansão urbana, associada a grandes obras de engenharia.

Com a construção de Palmas, um novo objeto espacial se inseriu no espaço urbano brasileiro, e no interior deste objeto configurou-se uma realidade urbana nova, dotada, por sua vez, de novos objetos. No entanto, nesse projeto recente, construído com a oportunidade de colocar em prática as modificações no ordenamento e no planejamento urbano-ambiental, acontece o contrário. Atenderam-se os pressupostos capitalistas e as desigualdades resultantes permearam sua sociedade e seu espaço (XAVIER, 2007).

$\mathrm{Na}$ verdade, o modelo capitalista de produção produziu um espaço urbano consumido e organizado pelos detentores do capital e o espaço urbano de Palmas tornou-se, um instrumento da desigualdade social (XAVIER, 2007). O sítio urbano de Palmas (Fig.1) possui limites bastante definidos e apresenta forte identidade paisagística situada entre mananciais hídricos entre relevos escarpados e de hidrografia abundante cortada por diversos canais fluviais como o Rio Tocantins, que margeia a área urbana na "configuração espacial" represado constituindo o reservatório da UHE de Luís Eduardo Magalhães. 


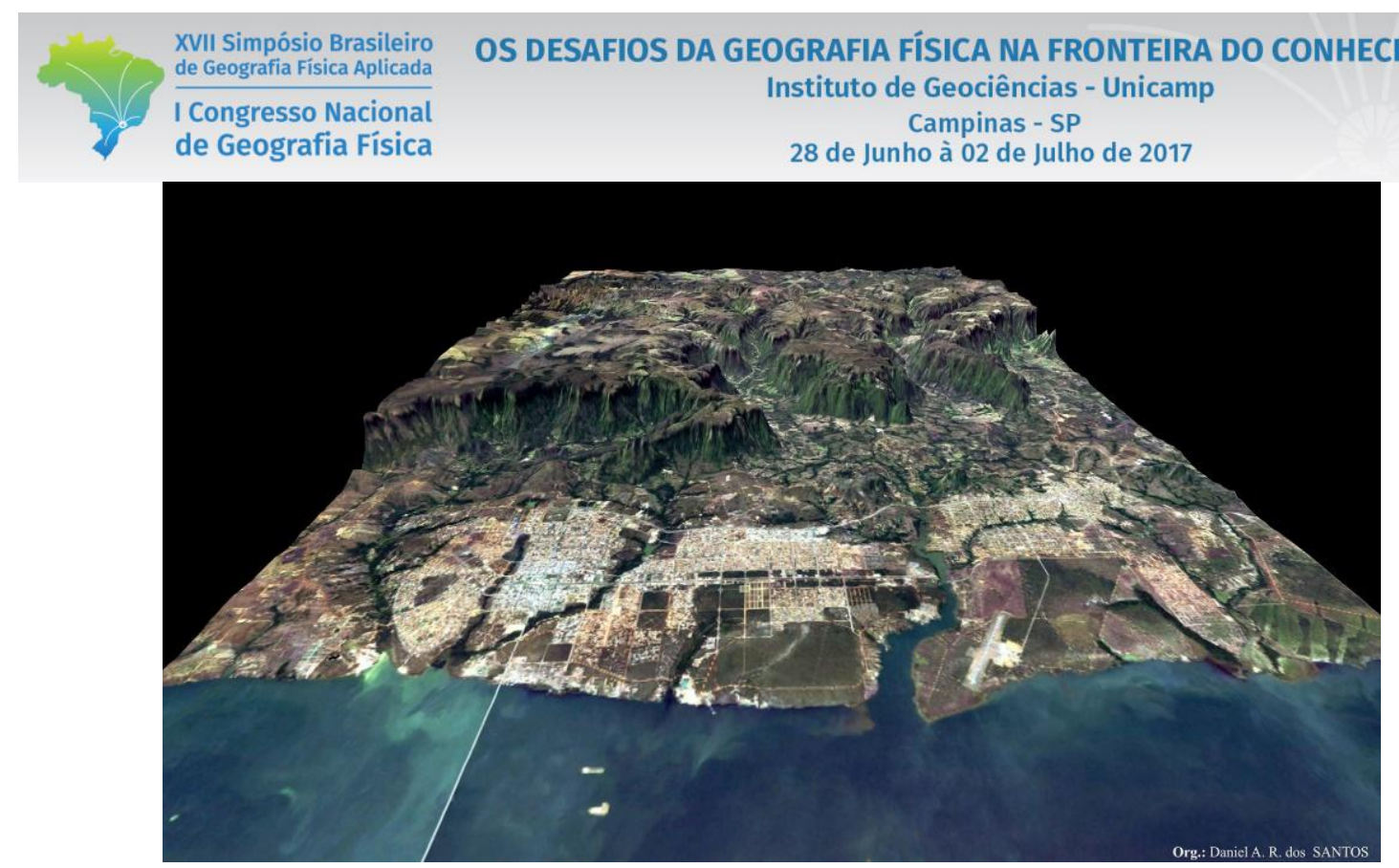

Figura 1: Configuração espacial em 3 dimensões da planta urbana de Palmas. Org. Daniel Santos (2014).

Projetada sistematicamente em estruturas e módulos (quadras e sub-quadras), tinha em seu projeto inicial a concepção de um sistema viário que permitiria segundo os $\operatorname{arquitetos}^{8}$ flexibilidade na implantação, todavia, por outro lado, criaram problemas para a gestão pública, que não conseguiu conter a expansão urbana desordenada ${ }^{9}$, aliado à ausência de planejamento gerando, nos dias atuais, espaços vazios ${ }^{10}$, comprometimento na infraestrutura e problemas relacionados com as principais funções urbanas como moradia, transporte, malha viária, saneamento e rede de drenagem.

Para entender esta problemática, é necessário buscar os ensinamentos de Rodrigues (1998, p.23), que diz ser necessário "compreender a dinâmica das relações societárias com a natureza". Em Palmas, percebe-se que o Estado separa o "tempo" do "espaço produzido". Esta afirmação é comprovada pela falta de articulação entre as gestões subsequentes a criação da cidade, que olhou a mesma separando o social da natureza, não compreendendo a multiplicidade social e as diversas formas pelas quais a sociedade se apropria e transforma a natureza e ao mesmo tempo produz o social. Marx em 1974, já nos ensinava que "toda produção, é a apropriação da natureza pelo

\footnotetext{
${ }^{8}$ A elaboração do plano e do projeto final da capital do Tocantins ficou à cargo do escritório de Planejamento do Grupo Quatro S/C LTDA, os coordenadores do projeto foram os arquitetos Luiz Fernando Cruvinel Teixeira e Walfredo Antunes de Oliveira, trabalharam ainda na equipe, arquitetos e engenheiros (Xavier, 2007, p.58)

${ }^{9}$ Palmas foi concebida para que em seu plano básico, o território fosse ocupado em parcelamentos e continuamente e somente depois destes ocupados é que áreas destinadas para expansão seriam ocupadas. Isto não ocorreu e o resultado é o espraiamento da cidade e sérios danos ao meio físico local, especialmente os mananciais hídricos como os córregos e ribeirões urbanos.

${ }^{10}$ Estes espaços são constantemente criados por um mercado imobiliário que especula o território e fragmenta-o de acordo com sua necessidade de mercado, quase sempre não observando em seus projetos os mananciais hídricos locais.
} 
indivíduo, no seio de uma determinada forma social e por intermédio dela”. (Marx, K 1974, p.112).

Palmas, portanto, é o reflexo de um crescimento capitalista específico de organização do espaço que reproduz as relações econômicas, sociais e políticas, favorecendo a degradação dos recursos hídricos que a cortam e margeiam, criando distorções na forma estrutural do e no espaço produzido. É o lugar, como qualquer outra cidade, de múltiplas relações entre os agentes políticos, sociais e econômicos. A produção do espaço urbano em Palmas seguiu concepções urbanas diferentes do projeto que à criou, que acabou por delimitar um traçado urbanístico onde forças capitalistas moldam e interferem na evolução, crescimento e desenvolvimento desta cidade. Estas forças têm seu cerne no principal agente produtor desta cidade: o Estado. Este, segundo Xavier (2007, p. 57),

...trabalhou como força fundamental de criação e desenvolvimento da cidade, priorizando a construção do sistema viário e da infraestrutura básica de abastecimento de água, energia elétrica e outros serviços. As empresas privadas foram chamadas a completar o investimento público na construção da cidade, visto que o Estado adotou a política privatista.

Magnavita (2001, p.705) sobre a concepção de criação de Palmas diz que o modelo adotado não passou de uma reprodução de modelos conceituais pré-existentes, criticados pelos urbanistas "pós-modernos" e arquitetos, incorporando muito mais problemas e limitações do que méritos e modernidade. Portanto, o projeto que previa modernidade, inovação e dinamismo ambiental para a capital do Tocantins, configurou-se apenas na reprodução do "discurso da cidade moderna", da hierarquias e segregações, dos zoneamentos e funções, dos símbolos do poder e de um sistema viário convencional e simplificado ${ }^{11}$. A estratégia de implantação do plano urbanístico previa uma expansão controlada para ocupação do território, conforme a demanda pelo crescimento surgisse, mas não ocorreu ${ }^{12}$ e hoje, 26 anos depois de sua criação, o

\footnotetext{
${ }^{11}$ A proposta de planejamento de Palmas visava inovação, mas na realidade não conseguiu ultrapassar as propostas urbanísticas existentes, formando-se como uma junção de várias correntes. Cobriu-se com o discurso ecológico de qualidade ambiental, com o de conforto e lazer para os habitantes, com o de flexibilidade na construção das quadras, mas na realidade toda sua construção envolveu-se com a construção do sistema viário. Ou seja, trata-se de um decalque, mesmo que imbuído de boas intenções, das propostas racionalistas seguindo as tendências Corbusianas, estético-viária e da Carta de Atenas (XAVIER, 2007, p.62).

12 Entretanto, essa estratégia foi rompida pela pressão do mercado imobiliário pois "os mecanismos de formação do preço e de acesso à terra dirigiram boa parte da demanda por moradia sobretudo para os bairros-satélites de Taquaralto e dos Aureny's, situados fora da área do plano básico. " (INSTITUTO DE PLANEJAMENTO DE PALMAS, 2002, p.16) in: XAVIER ( 2007, p. 12).
} 
que chama a atenção é um espaço espraiado e segregado, carente de funções urbanas básicas em quase toda malha urbana e uma degradação ambiental significativa ${ }^{13}$.

Seguindo a linha de pensamento de Lefebvre (1991, p.46) que nos ensina que a cidade sempre está relacionada à sociedade que a compõe em sua totalidade e que a mesma acompanha as mudanças desta, o que se vê, hoje em Palmas, é um espaço produzido e ocupado por agentes capitalistas que em descompasso com o projeto inicial causaram e causam impactos diretos e indiretos aos recursos hídricos locais, a exemplo de estreitamento de canais por assoreamento; problemas de drenagem ocasionando alagamentos e inundações; poluição de aquíferos e canais superficiais; esgotamento de efluentes não tratados e quando tratados, de forma ineficiente; canalização de canais e avanço de suas planícies por edificações, etc. Esta situação, logicamente, não difere de nenhuma outra cidade, o que nos leva a ratificar o que Santos (2005, p.105) nos ensina que "seja em maior ou menor grau de diferença e intensidade, todas as cidades brasileiras exibem problemáticas parecidas...são genéricas e revelam enormes carências."

Portanto, qual é o problema, qual a diferença? Qual a relevância deste estudo? A resposta, talvez, venha da reflexão de que, Palmas, mesmo concebida estruturalmente por meio de um projeto urbanístico ${ }^{14}$, dita "planejada", todavia apenas projetada, nasce com sérios problemas ${ }^{15}$ iguais ou mais graves que as cidades com processos de urbanização muito mais antigos. Eis aí a relevância desta pesquisa, ou seja, este sítio possui, problemas de ordem ambiental, aqui neste artigo, especificamente tratados - os hídricos, tão sérios, quanto as cidades que já possuem mais de 50, 100 anos e que não foram projetadas. Como uma cidade com apenas poucos anos apresenta problemas tão sérios ao ponto de causar entraves na gestão do espaço ocupado alterando a dinâmica dos recursos hídricos? Seria devido a forma pela qual os agentes do capital estão produzindo este espaço? Acreditamos que sim.

\footnotetext{
${ }^{13}$ Segundo Fighera (2005, p.91) “a Gestão Pública deteria o controle, detalhamento, aperfeiçoamento, correção do Plano Original, segundo as exigências de cada contexto. Por isso em março de 1989 foi criada a comissão de implantação da nova capital NOVATINS".

14 É fato também, que na história do planejamento urbano brasileiro desenvolveram-se planos que, de modo geral, não conseguiram constituir efetivas ferramentas para o fortalecimento da gestão territorial e urbana e, ainda, aprofundaram o modelo urbanístico perverso de cidades excludentes e segregadas (XAVIER, 2007, p.11).

${ }^{15}$... que vão desde a escolha geográfica ${ }^{15}$ para a implantação da nova capital brasileira ao processo político de sua criação, atendendo aos anseios de uma sociedade oligárquica que durante o regime militar teve sua importância "diminuída" e "esquecida" no processo de desenvolvimento do Brasil.
} 
O ritmo de crescimento atual de Palmas evidencia que as dispersões das frentes de urbanização não racionalizam o espaço, o que vem acarretando consequências sérias para o traçado urbano que vivencia um centro sem adensamento populacional e zonas limítrofes sem infraestrutura para se desenvolver em equilíbrio com o ambiente local. Estes fatores causam problemas na infraestrutura e na aplicação e execução dos serviços públicos, especialmente os relacionados aos recursos hídricos. Por sua vez, a segregação da população de baixa renda para as zonas limítrofes da cidade trouxe consigo uma degradação ambiental explícita em relação aos recursos naturais, sobretudo os hídricos, que se agrava dia-a-dia por causa de ocupações urbanas não planejadas que não observam políticas adequadas à realidade do espaço local, causando e agravando problemas para a drenagem urbana, para o abastecimento, para a coleta de resíduos sólidos e para o saneamento básico, além das ocupações inadequadas às áreas de proteção a mananciais e planícies de inundação.

Mesmo sendo uma cidade nova, problemas básicos em relação ao uso de suas águas urbanas já mencionados para as zonas periféricas de Palmas, passam também a existir em áreas centrais da cidade devido à ausência de uma gestão integrada entre a consolidação do espaço urbano, a necessidade de expansão, a preservação e o uso do solo e a sua relação direta com as águas urbanas. Essa configuração de problemas comprova a total desarticulação (descompasso) entre as políticas públicas e o os agentes públicos e privados que produzem o espaço urbano local.

Na realidade, Palmas convive com uma expansão urbana em constante contradições com suas reais necessidades de crescimento e desenvolvimento. O poder público permite ocupações de áreas públicas, privadas e principalmente de preservação ambiental, tanto no plano básico de ocupação $^{16}$, quanto nas áreas ocupadas destinadas para expansão, chegando a se conceber um descaso, com a própria cidade e com a aplicabilidade das políticas existentes quanto ao uso do solo e da água urbana, ligado diretamente aos conflitos de interesses políticos, ideológicos e socioeconômicos na produção do espaço urbano em Palmas.

\footnotetext{
${ }^{16}$ O sentido da ocupação do Plano Básico deveria ser Leste-Oeste, entretanto o núcleo se expandiu no sentido norte-sul, contrariando a lógica de implantação das infraestruturas. O Situa-se entre a serra e o rio, e entre os ribeirões Água Fria, ao norte, e Taquaruçu, ao sul. Da área destinada a implantação do plano básico os maiores percentuais se destinaram as áreas residenciais $36,8 \%$, áreas de preservação $23,7 \%$ e ao sistema viário que ocupa $10,9 \%$ do total.
} 
Estudos preliminares ${ }^{17}$ demonstraram que o projeto inicial não considerou a aplicação de políticas de estrutura, saneamento e drenagem relacionadas com os mananciais urbanos ${ }^{18}$. Em um primeiro momento a análise empírica aponta que esta situação se estabelece principalmente devido à ausência na aplicabilidade de uma gestão territorial integradora com os recursos naturais locais ao longo da evolução urbana da cidade. Essa análise, em um segundo momento, nos traz o entendimento de que Palmas têm como principal desafio nos dias atuais promover o adensamento de seus espaços urbanos integrando-os o meio natural por meio de políticas públicas e por uma gestão ambiental adequada a realidade local. Estes problemas resultaram de erros na implantação do projeto inicial e da maneira política pela qual, os governos municipal e estadual produzem o espaço, muitas vezes em detrimento das orientações de seu plano diretor (TEIXEIRA, 2009) e outras pela influência de um mercado imobiliário ${ }^{19}$.

Assim, a atual configuração espacial e ambiental de seu desenho urbano, na verdade contradiz a afirmação de que a estratégia de implantação de seu projeto inicial estabeleceria uma ocupação controlada e uma gestão dos recursos naturais locais, como afirma Teixeira (2009) ${ }^{20}$. Esta afirmação, explícita também em outras argumentações aqui apresentadas, que a cidade teve seu projeto de implantação e consolidação desvirtuado pelas gestões subsequentes a sua criação o que vem agravando o "estado-real dos recursos hídricos locais".

\section{Considerações Finais}

\footnotetext{
17 Estudos como a Qualidade de vida na cidade de Palmas, TO: uma análise através de indicadores habitacionais e urbanos. (FAIDA E FERREIRA, 2006); Palmas: uma capital para todos? Xavier (2007);

${ }^{18}$ Dentro desta problemática, a redução da disponibilidade quantitativa e qualitativa da água e dos mananciais urbanos tem sido tema de debate no meio político e científico estando diretamente associado ao ordenamento territorial e ao processo de urbanização de aglomerados urbanos. Escoamento superficial, impermeabilização do solo, geração de efluentes de ordem doméstica, industrial e comercial tratados ou não, dentre outros fatores como nos ensina Hardt et al (2008) são os principais problemas enfrentados pela ausência de uma gestão pública descentralizada e participativa que envolva não somente a administração pública, mas também a sociedade de modo geral.

${ }^{19}$ Decorrentes deste processo observam-se dilemas referentes ao planejamento urbano de Palmas. Os mecanismos de formação de preço e de acesso à terra, entenda-se especulação imobiliária, dirigiu boa parte da demanda por moradia, sobretudo para os Bairros Satélites.

${ }^{20}$ Segundo o autor a estratégia de implantação do plano previu uma expansão controlada da urbanização. Uma vez aberto o sistema viário básico, as quadras seriam progressivamente implantadas como módulos, de acordo com a demanda por espaços exigida pelo ritmo de crescimento urbano. Isto permitiria, em princípio, evitar a dispersão das frentes de urbanização pela área total prevista para a cidade, garantindo o aproveitamento racional e econômico da infraestrutura dos serviços públicos que avançaria, por assim dizer, em ondas. O sentido da expansão das quadras obedeceria inclusive às declividades apresentadas pelo terreno para adequação das instalações de infraestrutura que pudessem se servir da gravidade, como abastecimento de água, o esgotamento sanitário e a drenagem de águas pluviais (TEIXEIRA, 2009).
} 
Diante da problemática apresentada, entendemos que o principal agente produtor do espaço urbano em Palmas é o Estado e o capital imobiliário que trabalham em descompasso e aproveitam da ausência de uma gestão urbana e hídrica. Corroborando com Tucci (2005), o que se observa na atualidade no espaço urbano de Palmas, é que uma pequena parte de seu território se "estrutura e se organiza" dentro de normas e padrões estabelecidos e bem definidos, o que ele chama de "Cidade Legal". Por outro lado, a maioria de seu solo urbano é ocupado sem infraestrutura e sem planejamento por "diretrizes imobiliárias capitalistas" e por uma população de menor poder aquisitivo, que especialmente nos últimos dez anos não vem conseguindo se estabelecer nas áreas centrais e nobres da cidade devido ao alto preço do solo gerado pela especulação imobiliária, migrando para zonas limítrofes. É a "Cidade Ilegal".

Quanto aos recursos hidricos, este sofrem impactos e alterações diversas mediante a omissão e atuação da administração pública, que não possui uma gestão voltada para este recurso natural. Há apenas a apropriação voltada para ocupação, sem planejamento e diretrizes voltadas para o uso adequado dos mananciais urbanos.

Portanto, este estudo abre um leque de possibilidades para o surgimento de novas reflexões sobre a produção do espaço urbano em Palmas especificamente no que tange ao uso e apropriação dos recursos hídricos pela sociedade que produz dia-a-dia este espaço.

\section{REFERÊNCIAS}

ALMEIDA, F. G.; PEREIRA, L. M. O papel da distribuição e da gestão dos recursos hídricos no ordenamento territorial brasileiro. In: Ordenamento Territorial. Coletânea de textos com diferentes abordagens no contexto brasileiro. Org. ALMEIDA. FLÁVIO G. PEREIRA. LUIZ F. MARTINS. Bertand Brasil. Rio de Janeiro. 2009. Peg. 85-113.

BEER, A. R. Environmental Planning for site development. E\&FN Spon, London, 1990.

BOTTARI, T.S. Gestão Ambiental e Planejamento municipal: articulações e critérios necessários para a produção de cidades sustentáveis. Dissert. Mestrado na EESC USP, 2005.

BRUYNE, P.; HERMAN, J.; SCHOUTHEETE, M. Dinâmica da pesquisa em ciências sociais: os polos da prática metodológica. Rio de Janeiro: f. Alves, 1977, 252p.

CARNEIRO, P. R. F.; MIGUEZ, M. G. Controle de inundações em bacias hidrográficas metropolitanas. Annablume, São Paulo, 2011, 302 p.

CLARKE, R.; KING, J. O atlas da água. Tradução Anna Maria Quirino. Publifolha, São Paulo, 2005.

FINOTTI, R. A. et al. Monitoramento de recursos hídricos em áreas urbanas. Colaboradores Schneider, Vania Elisabete et al. Educs, Caxias do Sul, 2009. 272p. 
FRAN, F.; FERREIRA, F. P. Estudos como a Qualidade de vida na cidade de Palmas, TO: uma análise através de indicadores habitacionais e urbanos. Ambiente e Sociedade. Ano IX, nº 2. JUL/DEZ, 2006.

GALINDO, E. F. Gestão das águas urbanas: construindo uma gestão territorial e ambiental integrada. IV Encontro Nacional da Anppas. Brasília, 2008.

GODIM F. J.; MEDEIROS, V. V. R. Gestão da água no meio urbano e controle de inundações. In: Simpósio Brasileiro de Desastres naturais, 1. 2004, Florianópolis. Anais. Florianópolis GEDN/UFSC, 2004, p. 443-453 (CDROM).

GOUVÊA, R. G. A questão metropolitana no Brasil. Editora FCV, Rio de Janeiro, 2005, 324p.

Hardt et al (2008). Urbanização em áreas de mananciais hídricos: estudo de caso em Piraquara, Paraná. Cad. Metrópole 19. pp. 221-243. 10 sem. 2008. Disponível em: < http://www.cadernosmetropole.net/download/cm_artigos/cm19_127.pdf>. Acesso em 20 jan. 2013.

JACOBI, P. Apresentação. In: RIBEIRO, Wagner Costa. Geografia Política da água. Annablume, São Paulo, 2008. 162 p.

MAGLIO, I. C. O plano diretor e a sustentabilidade ambiental das cidades. Belém, 2007. Disponível em: http://www.belem.pa.gov.br/planodiretor/paginas/artigos.php. Acesso em: 03 de janeiro de 2013.

MARX, K. Para crítica da economia Política. In: Manuscritos econômicos e filosóficos. Coleção os Pensadores, v.7, 1974

RIBEIRO, W. C. Geografia política da água. Coleção Cidadania e Meio Ambiente. Annablume. São Paulo, 2008, $162 \mathrm{p}$.

RODRIGUES, A.M. Produção e consumo do e no espaço - problemática urbana. Hucitec. São Paulo, 1998, p.239

SOUZA, M. P. Instrumentos de Gestão Ambiental: fundamentos e práticas. São Carlos. Riani Costa, 2000.

TEIXEIRA, L. F. C. A formação de Palmas - dossiê cidades planejadas na hinterlândia. Revista UFG. Ano XI,

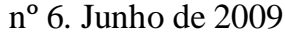

TUCCI, C. E. M. Gerenciamento integrado das inundações urbanas no Brasil. Rega/Global Water Partneship South América. Vol.1, n¹ Santiago; GWP/South América, 2004.

, C. E.M. Gestão de Águas Pluviais Urbanas. Ministério das Cidades - Global Water Partnership - Wolrd Bank - Unesco 2005. 192p.

TUNDISI, J. G.; TUNDISI, T. M. Recursos hídricos no século XXI. Oficina de Textos, São Paulo, 2011, 328p. 